\title{
Clinical and radiological efficacy of initial vs delayed treatment with infliximab plus methotrexate in patients with early rheumatoid arthritis
}

\author{
S M van der Kooij,, ${ }^{1}$ S le Cessie, ${ }^{1}$ Y P M Goekoop-Ruiterman, ${ }^{1} \mathrm{~J}$ K de Vries-Bouwstra, ${ }^{2}$ \\ D van Zeben, ${ }^{3}$ P J S M Kerstens, ${ }^{4}$ J M W Hazes, ${ }^{5}$ D van Schaardenburg, ${ }^{4}$ \\ F C Breedveld, ${ }^{1}$ B A C Dijkmans, ${ }^{2,4}$ C F Allaart ${ }^{1}$
}

${ }^{1}$ Leiden University Medical

Center, Leiden, The Netherlands;

${ }^{2}$ VU Medical Center,

Amsterdam, The Netherlands;

${ }^{3}$ Sint Franciscus Hospital,

Rotterdam, The Netherlands:

${ }^{4}$ Jan van Breemen Institute,

Amsterdam, The Netherlands;

${ }^{5}$ Erasmus Medical Center,

Rotterdam, The Netherlands

Correspondence to:

S M van der Kooij, Department of Rheumatology C-01-R, Leiden University Medical Center, PO Box 9600, 2300 RC Leiden, The Netherlands; smvanderkooij@ lumc.nl

Accepted 22 August 2008 Published Online First

17 October 2008

\section{ABSTRACT}

Objectives: To compare the clinical and radiological efficacy of initial vs delayed treatment with methotrexate (MTX) and infliximab (IFX) in patients with recent onset rheumatoid arthritis (RA).

Methods: In a post hoc analysis of the BeSt study (for Behandel Stratagieen, Dutch for treatment strategies), 117 patients who started initial MTX+IFX were compared with 67 patients who started MTX+IFX treatment after failing (disease activity score (DAS) $>2.4$; median delay to IFX: 13 months) on $\geqslant 3$ traditional DMARDs. If the DAS remained $>2.4$, the protocol dictated IFX dose increases to $6,7.5$ and $10 \mathrm{mg} / \mathrm{kg}$. In case of a DAS $\leqslant 2.4$ for $\geqslant 6$ months, IFX was tapered and finally stopped. We aimed to correct for allocation bias using propensity scores. Functional ability was measured by the Health Assessment Questionnaire (HAQ), radiological progression by Sharp/van der Heijde scoring (SHS).

Results: Baseline differences between the initial and delayed groups were no longer significant after propensity score adjustment. At 3 years after baseline, patients treated with initial MTX+IFX experienced more improvement in HAO over time and were less likely to have SHS progression than patients treated with delayed MTX+IFX $(p=0.034)$. At 2 years after IFX initiation, more patients in the initial group compared with the delayed group could discontinue IFX after a good response $(56 \%$ vs $29 \%$, $p=0.008$ ).

Conclusions: The results of this post hoc analysis suggest that using MTX+IFX as initial treatment for patients with recent onset RA is more effective than reserving MTX+IFX for patients who failed on traditional DMARDs, with more HAO improvement over time, more IFX discontinuation and less progression of joint damage.

In the past few decades, the treatment outcomes of patients with rheumatoid arthritis (RA) have improved dramatically. Several studies have clearly shown that immediate introduction of diseasemodifying antirheumatic drugs (DMARDs) after diagnosis is superior to delayed introduction, ${ }^{1-3}$ which led to the hypothesis that a window of opportunity exists in which the disease process can be altered. ${ }^{45}$

The tumour necrosis factor (TNF) antagonists infliximab (IFX), adalimumab and etanercept each have proven to reduce disease activity and suppress radiographic joint damage more adequately than methotrexate (MTX) alone in patients with recent onset $^{6-8}$ and established RA. ${ }^{9-11}$ However, the costs of TNF antagonists are considerable and there is ongoing debate on their safety. ${ }^{12-14}$ Additionally, in approximately a third of patients MTX monotherapy will provide sufficient improvement. ${ }^{15}{ }^{16}$ Currently, in The Netherlands and in many other countries TNF antagonists are reimbursed only for patients who have failed to respond to at least two traditional DMARDs.

It may be questioned whether "delayed anti-TNF treatment" after failure on traditional DMARDs is the most effective way of employing these potent drugs. Quinn and colleagues demonstrated that with initial MTX+IFX therapy, remission was achieved in 9 out of 10 patients after 1 year and sustained in 7 out of 9 patients after discontinuation of IFX. ${ }^{17}$ In the BeSt study (for Behandel stratagieen, Dutch for treatment strategies), $56 \%$ of patients with early RA who were treated with initial MTX+IFX therapy discontinued IFX within the first year and maintained a good response throughout the second year. ${ }^{18}$ Although it is conceivable that initial treatment with TNF antagonists is superior to delayed treatment, reports directly comparing initial vs delayed institution of TNF antagonists are scarce. ${ }^{19} 20$

The current analysis is a post hoc analysis of the BeSt study ${ }^{21} 22$ and aims to compare initial treatment with MTX+IFX in group 4 with delayed treatment with MTX+IFX after failure on previous DMARDs in groups 1, 2 and 3. Because it is likely that patients who proceed to delayed MTX+IFX represent a selection of patients with more severe RA, we aimed to correct for allocation bias using propensity scores. ${ }^{23} 24$

\section{METHODS}

This is a post hoc analysis from the BeSt study; a randomised controlled trial comparing four different treatment strategies in patients with active, recent onset RA. The detailed inclusion criteria have been described previously. ${ }^{21}$ The medical ethics committees of all participating centres approved the study protocol and all patients gave written informed consent before inclusion.

Treatment strategies were sequential monotherapy (group 1, $\mathrm{n}=126$ ), step-up combination therapy (group 2, $\mathrm{n}=121$ ), initial combination therapy including prednisone (group $3, n=133$ ) and initial combination therapy with MTX+IFX (group $4, \mathrm{n}=128$ ). Every 3 months, the disease activity score (DAS, 44 joint count) ${ }^{25}$ was calculated. In case of a DAS of $>2.4$ or intolerable side effects, treatment was adjusted to the next step in the protocol. 


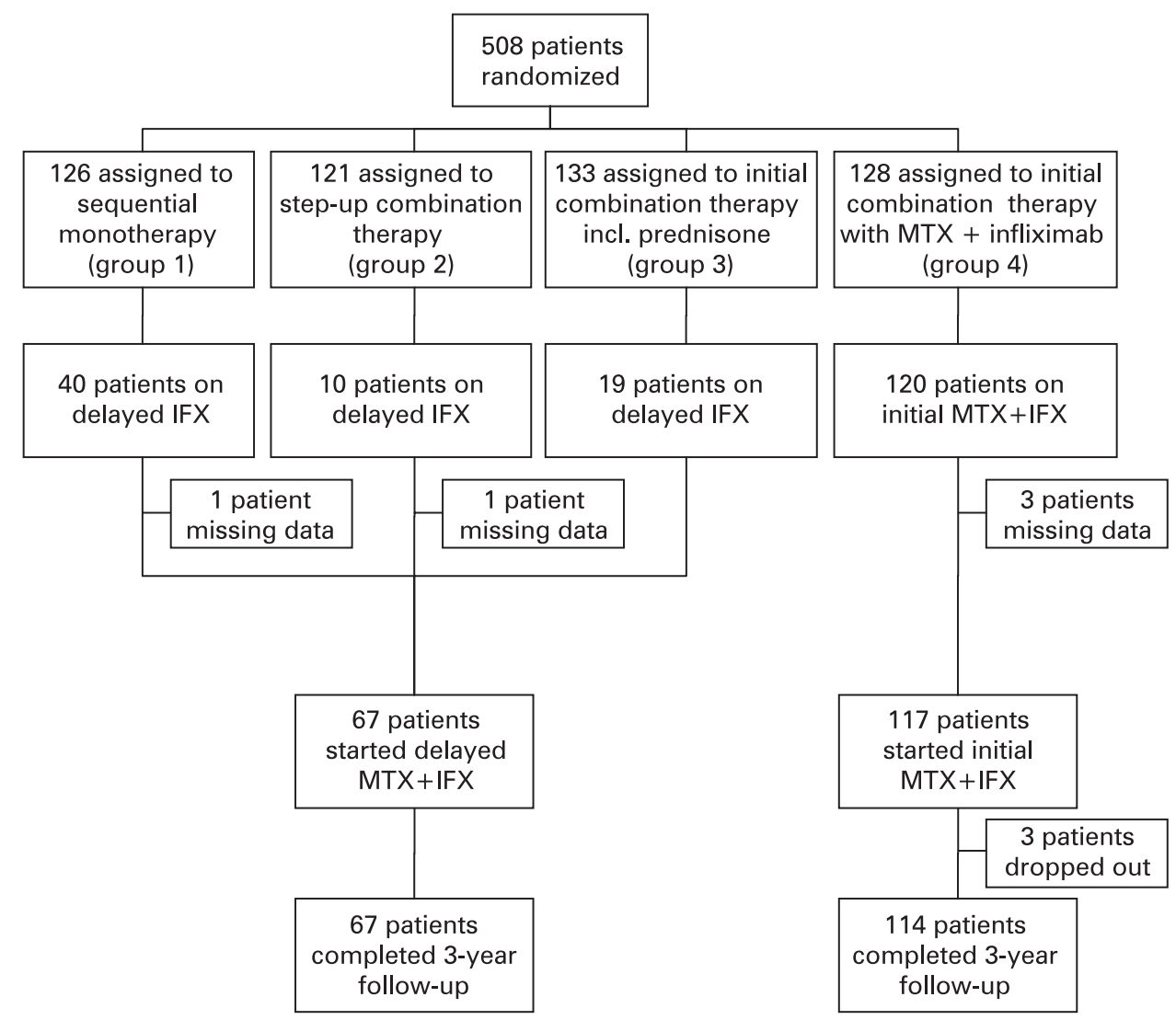

Figure 1 Flowchart of the study. Reasons for dropout were: deceased due to disseminated tuberculosis $(n=1)$, deceased due to myocardial infarction $(n=1)$ and patient refusal $(n=1)$. IFX, infliximab; MTX, methotrexate.

Patients randomised to groups 1, 2 and 3 started treatment with "delayed MTX+IFX" after at least three traditional DMARDs were tried and failed: in group 1, MTX monotherapy $25 \mathrm{mg} /$ week, then sulfasalazine (SSA) monotherapy 2000$3000 \mathrm{mg} /$ day, then leflunomide monotherapy $20 \mathrm{mg} /$ day; in group 2, MTX monotherapy $25 \mathrm{mg} /$ week, then MTX+SSA 2000-3000 mg/day, then MTX+SSA+hydroxychloroquine (HCQ) $400 \mathrm{mg} /$ day, then $\mathrm{MTX}+\mathrm{SSA}+\mathrm{HCQ}+$ prednisone $7.5 \mathrm{mg} /$ day; and in group 3, MTX+SSA+prednisone $60 \mathrm{mg} /$ day, tapered to $7.5 \mathrm{mg} /$ day in 7 weeks, then MTX+ciclosporine $2.5 \mathrm{mg} / \mathrm{kg} /$ day plus prednisone $7.5 \mathrm{mg} /$ day. MTX was always combined with folic acid $1 \mathrm{mg} /$ day.

In all groups, treatment with MTX+IFX consisted of MTX $25 \mathrm{mg} /$ week and IFX $3 \mathrm{mg} / \mathrm{kg}$ (at $\mathrm{t}=0,2$ and 6 weeks, then every 8 weeks). If the DAS was $>2.4$ a week before the next infusion, the next dose of IFX was increased (to $6 \mathrm{mg} / \mathrm{kg}$, $7.5 \mathrm{mg} / \mathrm{kg}$ and finally $10 \mathrm{mg} / \mathrm{kg}$ ). If the DAS was $\leqslant 2.4$ for at least 6 months consecutively, IFX was tapered and finally discontinued.

Patients who started initial MTX+IFX in group 4, as well as patients who started delayed MTX+IFX in the other groups, within 2 years from enrolment in the BeSt study, were included. All patients were followed prospectively for 3 years from the moment of inclusion in the BeSt study.

\section{Study endpoints}

The primary endpoints were functional ability, measured by the Health Assessment Questionnaire (HAQ), ${ }^{26}$ and progression of radiographic joint damage, scored on anonymised radiographs of the hands and feet at baseline and after 3-years follow-up according to the van der Heijde modified Sharp Score (SHS), ${ }^{27}$ in random order, by two independent readers. The interobserver intraclass correlation coefficient was 0.96 . Progression of joint damage was defined as a change in total SHS greater than the smallest detectable change (SDC), ${ }^{28}$ which was 4.3 units. Secondary outcomes were the discontinuation of IFX due to a good response (measured in all patients who started IFX, in a 2-year period from the moment MTX+IFX was started), the cumulative IFX doses received and treatment related serious adverse events.

\section{Statistical analysis}

Baseline characteristics were compared using the $\chi^{2}$ test, the Student $t$ test or the Mann-Whitney $U$ test depending on the tested variable. Since patients in the delayed MTX+IFX group were likely to represent a selection of patients with more severe RA, we aimed to adjust for allocation bias using propensity scoring. ${ }^{23}$ We selected 30 baseline demographic and disease characteristics in total and put these into a logistic regression model to predict the probability of patients in groups 1 to 3 proceeding to delayed MTX+IFX. This model was then used to calculate the predicted probability (propensity) of delayed MTX+IFX treatment for each patient in groups 1 through 4 . Next, patients who actually received MTX+IFX were divided into five quintiles based on the probability of receiving delayed MTX+IFX. Within each quintile, baseline variables are expected to be balanced between the initial and delayed group, in which case any within-quintile difference in outcome is assumed to be due to the difference in treatment. Variables within the quintiles were compared between the two groups using the 


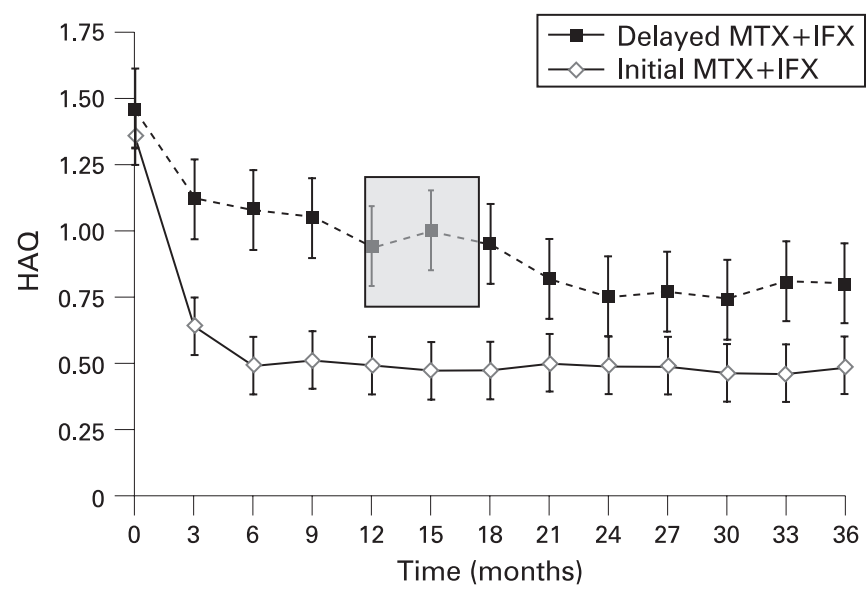

Figure 2 Functioning as measured by the Health Assessment Questionnaire (HAO) during 3-years follow-up in the initial and delayed infliximab (IFX) groups, corrected for propensity score. To obtain corrected $\mathrm{HAO}$ values, means adjusted for propensity quintile were estimated by repeated measures models. The grey rectangle represents the period (median 13 months, interquartile range (IQR) 12 to 17 months) during which patients in the delayed group started methotrexate (MTX)+IFX.

Mantel-Haenzel test. The fit of the model was assessed by the Hosmer-Lemeshow test; the discriminatory ability was assessed by calculating the area under a receiver operating characteristic (ROC) curve. We performed longitudinal data analysis of the $\mathrm{HAO}$ using a repeated measures analysis, with treatment, time and their interaction as fixed effects. Means adjusted for propensity quintile were estimated by these models. Logistic regression was used to analyse radiographic progression $>$ SDC and IFX discontinuation adjusted for propensity quintile. In view of the possibility of selection bias as a result of treatment dynamics, we also investigated the primary endpoints of the delayed group separately for groups 1,2 and 3 . The cumulative IFX doses ( $\mathrm{mg} / \mathrm{kg}$ during 3-year follow-up) were calculated and compared between both groups using the Student $t$ test.

\section{RESULTS}

Complete baseline data for calculating propensity scores were available in 117 patients $(98 \%)$ treated with initial MTX+IFX and 67 patients (97\%) treated with delayed MTX+IFX (fig 1).
Three patients did not complete 3-years follow-up. Patients in the delayed MTX+IFX group tended to be more often females of younger age, with more active disease at inclusion (table 1 ).

The median (IOR) delay of MTX+IFX therapy in the delayed group was 13 (12-17) months. At the time of MTX+IFX initiation, functioning in the delayed group had already improved (average delta HAO of -0.38) due to on average 13 months of traditional DMARD therapy. Within the delayed group, patients from groups 1,2 and 3 had comparable demographic and disease characteristics at baseline, except for a lower median SHS in group 3 compared with groups 1 and 2 $(1.5$ vs 4.5 and 5.5 , respectively; $\mathrm{p}<0.05)$.

\section{Propensity model}

The propensity model had an overall accuracy of $83 \%$ and included the following 30 baseline covariates: gender; age at inclusion; symptom duration; disease duration; height; weight; body mass index (BMI); alcohol consumption; smoking; rheumatoid factor (RF) status; anti-cyclic citrullinated peptide (anti-CCP) status; previous antimalarial therapy; hormonal replacement therapy; DAS; DAS in 3 categories $(\leqslant 3.8,3.8-5.1$ and >5.1); ESR; Ritchie articular index; swollen joint count; patient's assessments of global health, pain, disease activity, morning stiffness and doctor's assessment of disease activity on a 0-100 mm VAS; HAQ; erosive disease; erosion score; narrowing score; total SHS; as well as interaction terms for smoking and RF status and for gender and menopausal status. The model fit by the Hosmer-Lemeshow test was good $(p=0.85)$. The area under the ROC curve $(95 \%$ CI) was 0.77 ( 0.71 to 0.83 ), indicating good discrimination. The 184 patients were divided into 5 quintiles based on the propensity score, derived from the logistic regression analysis. Table 2 shows the distribution of the baseline variables in five propensity quintiles. As expected, patients with the highest propensity to proceed to delayed MTX+IFX had more active disease, higher HAQ scores, were more often female and RF positive and were of younger age. Within the five propensity quintiles, baseline demographic and disease characteristics were comparable between the initial and delayed groups ( $p>0.05$, by Mantel-Haenzel test).

\section{Functional ability}

Patients in the initial group showed more improvement in functioning from baseline than patients in the delayed group, as observed by longitudinal data analysis adjusted for disease

Table 1 Demographic and disease characteristics at the time of inclusion in the BeSt study of patients treated with initial IFX and delayed IFX

\begin{tabular}{llll}
\hline & Initial IFX (n= 117) & Delayed IFX (n= 67) & p Value \\
\hline Female sex (\%) & 68 & 81 & 0.057 \\
Age at diagnosis, mean (SD) & $53.8(14.1)$ & $49.8(12.4)$ & 0.054 \\
RF positive (\%) & 64 & 75 & 0.141 \\
Symptom duration (weeks), median (IQR) & $23(13$ to 45$)$ & $29(17$ to 56$)$ & 0.175 \\
Disease duration (weeks), median (IOR) & $3(1$ to 5$)$ & $2(1$ to 5$)$ & 0.069 \\
Tender joints (no.), mean (SD) & $13(6)$ & $16(7)$ & $<0.001$ \\
Swollen joints (no.), mean (SD) & $14(7)$ & $16(6)$ & 0.049 \\
ESR, median (IQR) & $35(19$ to 56$)$ & $40(22$ to 68$)$ & 0.157 \\
DAS, mean (SD) & $4.29(0.8)$ & $4.73(0.8)$ & 0.001 \\
HAO, mean (SD) & $1.36(0.7)$ & $1.49(0.5)$ & 0.159 \\
Erosion score, median (IOR) & $2.0(0.5$ to 5.0$)$ & $1.5(0.5$ to 3.5$)$ & 0.294 \\
Narrowing score, median (IOR) & $1.5(0.0$ to 3.8) & $1.5(0.0$ to 4.0$)$ & 0.953 \\
Total Sharp score, median (IOR) & $4.0(1.5$ to 9.0$)$ & $3.0(1.0$ to 7.5$)$ & 0.568 \\
\hline
\end{tabular}

Best, Behandel Stratagieen (treatment strategies); DAS, disease activity score; ESR, erythrocyte sedimentation rate; HAO, health assessment questionnaire; IFX, infliximab; IQR, interquartile range; RF, rheumatoid factor. 
Table 2 Distribution of characteristics at study inclusion within propensity quintiles

\begin{tabular}{llllll}
\hline & \multicolumn{3}{l}{ Quintile } & & \\
\cline { 2 - 6 } & $\mathbf{1}$ & $\mathbf{2}$ & $\mathbf{3}$ & $\mathbf{4}$ & $\mathbf{5}$ \\
\hline Initial IFX (n=117) & 28 & 29 & 13 & 22 & 25 \\
Delayed IFX (n = 67) & 2 & 6 & 9 & 18 & 32 \\
Propensity score, median & 0.03 & 0.08 & 0.14 & 0.23 & 0.44 \\
Female sex (\%) & 47 & 54 & 73 & 80 & 91 \\
Age at diagnosis, mean & 60.3 & 55.4 & 55.0 & 52.3 & 45.3 \\
RF positive (\%) & 50 & 63 & 82 & 63 & 79 \\
Symptom duration (weeks), median & 28 & 27 & 24 & 22 & 24 \\
Tender joints (no.), mean & 10 & 11 & 14 & 15 & 17 \\
Swollen joints (no.), mean & 10 & 13 & 14 & 17 & 17 \\
ESR, median & 23 & 31 & 31 & 41 & 45 \\
DAS, mean & 3.69 & 4.11 & 4.36 & 4.76 & 4.88 \\
HAO, median & 1.25 & 1.25 & 1.44 & 1.50 & 1.38 \\
\hline
\end{tabular}

DAS, disease activity score; ESR, erythrocyte sedimentation rate; HAQ, health assessment questionnaire; IFX, infliximab; RF, rheumatoid factor.

severity at baseline (fig 2). At 3 years, patients in the initial group had improved with a mean of $0.87 \mathrm{HAQ}$ units vs 0.66 $\mathrm{HAO}$ units in the delayed group $(p<0.05)$, a difference comparable with the minimal clinically important difference of $0.22 .{ }^{29}$ The area under the curve (AUC) for the HAO of the initial group was significantly smaller compared with the AUC of the delayed group $(\mathrm{p}<0.001$, fig 2$)$. Within the delayed group, we observed no differences in improvement in HAQ between patients randomised to group 1, 2 or 3 .

\section{Joint damage}

Radiographs of the hands and feet at baseline and 3-year followup were available in 109 patients from the initial group and 66 patients from the delayed group. Median (IOR) 3-year SHS progression was 1.5 (0.0 to 4.8$)$ in the initial group vs 4.5 (0.9 to $15.4)$ in the delayed group $(p<0.001)$. The percentage of patients with SHS progression $>$ SDC after 3 years was $26 \%$ in the initial group vs $50 \%$ in the delayed group $(p=0.001)$. After adjustment for propensity score, significant progression of joint damage (SHS $>$ SDC) was two times less likely in patients in the initial group compared with patients in the delayed group (odds ratio (OR) $0.47,95 \%$ CI 0.24 to $0.95, p=0.034$, table 3 ). Within the delayed group, group 3 showed a trend for fewer patients with significant joint damage progression compared with groups 1 and 2 (33\% vs $56 \%$ and $56 \%$, overall $p=0.25$ ).

\section{IFX dose and treatment discontinuation}

After adjustment for propensity score, patients treated with initial MTX+IFX were significantly more likely to have discontinued IFX due to a sustained DAS $\leqslant 2.4$ (OR 2.6, 95\% CI 1.3 to $5.2, p=0.008$, table 3 ). In 28 of 66 patients ( $42 \%)$ in the initial group and in 9 of 19 patients (47\%) in the delayed group, successful IFX discontinuation was achieved only after an IFX dose increase. The percentages of patients failing on MTX+IFX, as well as the reasons for failure in the two groups were comparable (table 4). Over the 3 years, patients treated with initial MTX+IFX received on average 9 IFX infusions corresponding to a median cumulative IFX dose of $40 \mathrm{mg} / \mathrm{kg}$; patients treated with delayed MTX+IFX received on average 11 IFX infusions corresponding to a median cumulative IFX dose of $48 \mathrm{mg} / \mathrm{kg}$.

\section{Toxicity}

Serious adverse events (SAEs) were reported in 19 patients $(16 \%)$ in the initial group and 17 patients $(25 \%)$ in the delayed group. A possible or probable relation to treatment with MTX+IFX was reported in seven patients $(6 \%)$ in the initial group (instable angina pectoris (two SAEs in one patient), pneumonia (one), MTX pneumonitis (one), septic arthritis (one), basal cell carcinoma (one), infusion reaction (one) and disseminated tuberculosis, eventually resulting in the patients' death after infectious complications) ${ }^{30}$ and in seven patients $(10 \%)$ in the delayed group ( $p=0.27$ ) (pneumonia (two), basal cell carcinoma (one), facial hyperaemia during infliximab infusion (one), ulcerative stomatitis (one), osteomyelitis (one) and disseminated tuberculosis (one), of which the patient recovered after intensive tuberculostatic treatment). ${ }^{22}$

\section{DISCUSSION}

This post hoc analysis suggests that in patients with recent onset RA, a strategy of initial MTX+IFX results in significantly more improvement in functional ability and less radiographic damage progression over 3 years time than reserving MTX+IFX for patients who failed on at least three traditional DMARDs. In addition, more patients initially treated with IFX successfully tapered and discontinued IFX due to a sustained DAS of $\leqslant 2.4$.

The patients who later started IFX had a median delay of only 13 months and median disease duration of 14 months. At this stage, the HAO is thought to be mostly related to disease activity and not structural damage and therefore still sensitive

Table 3 Radiographic progression greater than the smallest detectable change (SDC) after 3 years and IFX discontinuation 2 years after the start of MTX+IFX in the initial and delayed MTX+IFX groups, adjusted for propensity score

\begin{tabular}{lllll}
\hline & Initial IFX & Delayed IFX & Odds ratio (95\% CI) & p Value \\
\hline Patients with progression SHS $>$ SDC, \% & 26 & 50 & 0.47 (0.24 to 0.95) & 0.034 \\
Patients who discontinued IFX due to a sustained & 56 & 29 & 2.56 (1.27 to 5.16) & 0.008 \\
DAS $\leqslant 2.4, \%$ & & &
\end{tabular}

DAS, disease activity score; IFX, infliximab; SDC, smallest detectable change; SHS, modified Sharp/van der Heijde Score. 
Table 4 Treatment outcome and required IFX doses 2 years after starting initial or delayed MTX+IFX

\begin{tabular}{|c|c|c|c|}
\hline & $\begin{array}{l}\text { Initial IFX } \\
(n=117)\end{array}$ & $\begin{array}{l}\text { Delayed IFX } \\
(n=67)\end{array}$ & p Value \\
\hline $\begin{array}{l}\text { Stopped IFX and still DAS } \leqslant 2.4 \text {, } \\
\text { no. }(\%)\end{array}$ & $66(56)$ & $19(29)$ & $<0.001$ \\
\hline Max dose IFX 3 mg/kg, no. & 38 & 10 & \\
\hline Max dose IFX 6 mg/kg, no. & 21 & 8 & \\
\hline Max dose IFX 7.5 mg/kg, no. & 4 & 1 & \\
\hline Max dose IFX 10 mg/kg, no. & 3 & - & \\
\hline Remained on MTX+IFX, no. (\%) & $22(19)$ & $27(40)$ & 0.002 \\
\hline Max dose IFX 3 mg/kg, no. & 7 & 5 & \\
\hline Max dose IFX 6 mg/kg, no. & 4 & 4 & \\
\hline Max dose IFX 7.5 mg/kg, no. & 6 & 5 & \\
\hline Max dose IFX 10 mg/kg, no. & 5 & 13 & \\
\hline Failed on MTX+IFX, no. (\%) & $29(25)$ & $21(31)$ & 0.336 \\
\hline Due to toxicity, no. & 8 & 6 & \\
\hline Due to inefficacy, no. & 21 & 13 & \\
\hline Due to other reasons, no. & - & 2 & \\
\hline
\end{tabular}

DAS, disease activity score; IFX, infliximab; MTX, methotrexate.

to change. ${ }^{31} 32$ Our results suggest that even a relatively short delay will reduce the possibility of improvement, which supports the "window of opportunity" hypothesis. A previous study on immediate vs delayed IFX institution suggested the same. ${ }^{20}$

An important limitation of this post hoc analysis of a randomised trial is the fact that the delayed group represents a selection of patients with possibly more severe RA, which hampers the interpretation of the results. In daily practice patient selection is also an issue, since in The Netherlands, as in most other countries, IFX is available only for patients who failed on at least two traditional DMARDs including MTX. In this analysis we used propensity scores, which reduce selection bias and help to interpret results adjusted for disease severity. ${ }^{23}$ Using propensity adjustment, the differences between groups at baseline were no longer significant, and the adjusted outcomes still suggested that initial IFX provides more benefit than delayed IFX. However, propensity scoring cannot eliminate any bias as a result of the treatment dynamics in the different groups during follow-up, as would also occur in daily practice. To try to address this point, we compared the results on functional ability and radiographic progression in the delayed group separately for groups 1, 2 and 3, and observed no significant differences between the three groups, although there was a trend for fewer patients with joint damage progression during 3 years in group 3, compared with groups 1 and 2 .

There appeared to be a twofold decreased risk of significant joint damage progression in the initial MTX+IFX group. Unfortunately, only the baseline and 3-year radiographs were available for scoring. As a consequence, it is uncertain if there was a relation in time between use or discontinuation of IFX and radiographic progression. Therefore, the differences in radiographic progression should be interpreted with caution.

Finally, in the 3-year follow-up from baseline, patients in the delayed group had less time to receive IFX compared with the initial group. However, follow-up from the moment IFX was started in the delayed group was on average 2 years, which should be sufficiently long to observe a treatment effect and allow patients to taper and stop IFX. Since more patients in the initial group tapered and discontinued IFX due to a good response, the cumulative 3-year IFX doses in both groups were comparable, despite earlier introduction of IFX in the initial group. Given the observation that patients treated with delayed MTX+IFX less often can taper and discontinue IFX, which corresponds with daily practice, ${ }^{33}$ differences in the timing of IFX may also have financial consequences for the future.

The study protocol dictated dose escalation of IFX if the DAS remained $>2.4$. Although in the Anti-TNF Trial in Rheumatoid Arthritis with Concomitant Therapy (ATTRACT) study no significant differences in outcomes between IFX $3 \mathrm{mg} / \mathrm{kg}$ and $10 \mathrm{mg} / \mathrm{kg}$ were observed, ${ }^{11}$ it has been suggested that a subset of patients benefits from higher IFX doses. ${ }^{345}$ The benefit of dose escalation is confirmed in our study, because $44 \%$ of the patients who successfully discontinued IFX first needed dose increases $>$ $3 \mathrm{mg} / \mathrm{kg}$ to achieve a clinical response. This study was not designed for, nor capable of comparing toxicity between both strategies. Treatment related toxicity between both groups seemed comparable. Two patients (one in either group) developed disseminated tuberculosis. The patient in the delayed group recovered after tuberculostatic therapy, but the patient in the initial group died after a complicated disease course..$^{30}$

It is evident that prescription of initial MTX+IFX to all patients with recently diagnosed RA will result in overtreatment of about a third of the patients, who would have done well on MTX alone. ${ }^{15}{ }^{16}$ It can be expected that such patients will be able to discontinue IFX quite early, keeping the period of overtreatment to a minimum. Based on this analysis, we would now suggest that initial undertreatment could be worse than temporary overtreatment. Ideally, in the future we should be able to reliably identify patients with RA who will (1) experience a severe disease course and thus need TNF antagonists at the time of diagnosis, (2) experience a mild disease course and hence not need TNF antagonists, or (3) fail to respond to TNF antagonists and require alternative (biological) therapies.

In summary, this post hoc analysis suggests that initial MTX+IFX treatment in patients with recent onset RA is more effective than reserving this combination for patients who previously failed on traditional DMARDs, resulting in more functional improvement, less progression of joint damage and more patients able to discontinue IFX with maintenance of good response. These advantages should first be confirmed in other studies, and could have an additional benefit in terms of long-term cost effectiveness of IFX treatment.

Acknowledgements: We would like to thank all patients as well as the following rheumatologists (other than the authors) who participated in the Foundation for Applied Rheumatology Research (all locations are in The Netherlands): WM de Beus (Medical Center Haaglanden, Leidschendam); C Bijkerk (Reinier de Graaf Gasthuis, Delft); MHW de Bois and G Collée (Medical Center Haaglanden, The Hague); JAPM Ewals (Haga Hospital, The Hague); AH Gerards (Vlietland Hospital, Schiedam); BAM Grillet (De Honte Hospital, Terneuzen); JHLM van Groenendael (Franciscus Hospital, Roosendaal); KH Han (Medical Center Rijnmond-Zuid, Rotterdam); TWJ Huizinga (Leiden University Medical Center, Leiden); HMJ Hulsmans (Haga Hospital, The Hague); MH de Jager (Albert Schweitzer Hospital, Dordrecht); JM de Jonge-Bok (retired); MV van Krugten (Walcheren Hospital, Vlissingen); H van der Leeden (retired); WF Lems (Slotervaart Hospital, Amsterdam); MF van Lieshout-Zuidema (Spaarne Hospital, Hoofddorp); A Linssen (retired); PAHM van der Lubbe (Vlietland Hospital, Schiedam); C Mallée (Kennemer Gasthuis, Haarlem); ETH Molenaar (Groene Hart Hospital, Gouda); HC van Paassen (Sint Franciscus Gasthuis, Rotterdam); AJ Peeters (Reinier de Graaf Gasthuis, Delft); HK Markusse (deceased); HK Ronday (Haga Hospital, The Hague); PEH Seys (Lievensberg Hospital, Bergen op Zoom); RM van Soesbergen (retired); PBJ de Sonnaville (Oosterschelde Hospital, Goes); I Speyer (Bronovo Hospital, The Hague); KSS Steen (Kennemer Gasthuis, Haarlem); JPh Terwiel (Spaarne Hospital, Hoofddorp); AE Voskuyl (VU Medical Center, Amsterdam); ML Westedt (Bronovo Hospital, The Hague); S ten Wolde (Kennemer Gasthuis, Haarlem); JMGW Wouters (Sint Franciscus Gasthuis, Rotterdam). We would also like to thank all other rheumatologists and trainee rheumatologists who enrolled patients in this study and all research nurses for their contributions.

Funding: The BeSt study was supported by the Dutch College of Health Insurances Schering-Plough and Centocor provided additional funding.

Competing interests: CFA and FCB have received lecture fees from Schering-Plough; $B A D$ has received funds for research and lecture fees from Schering-Plough. The 
authors were responsible for the study design, the collection, analysis and interpretation of all data, the writing of this article and the decision to publish.

Ethics approval: The medical ethics committees of all participating centres approved the study protocol and all patients gave written informed consent before inclusion.

\section{REFERENCES}

1. Finckh A, Liang $\mathrm{MH}$, van Herckenrode $\mathrm{CM}$, de Pablo P. Long-term impact of early treatment on radiographic progression in rheumatoid arthritis: a meta-analysis Arthritis Rheum 2006:55:864-72.

2. Lard LR, Visser H, Speyer I, van der Horst-Bruinsma IE, Zwinderman AH, Breedveld $\mathrm{FC}$, et al. Early versus delayed treatment in patients with recent-onset rheumatoid arthritis: comparison of two cohorts who received different treatment strategies. Am J Med 2001;111:446-51.

3. Nell VP, Machold KP, Eberl G, Stamm TA, Uffmann M, Smolen JS. Benefit of very early referral and very early therapy with disease-modifying anti-rheumatic drugs in patients with early rheumatoid arthritis. Rheumatology (Oxford) 2004;43:906-14.

4. Boers M. Understanding the window of opportunity concept in early rheumatoid arthritis. Arthritis Rheum 2003:48:1771-4.

5. Quinn MA, Emery P. Window of opportunity in early rheumatoid arthritis: possibility of altering the disease process with early intervention. Clin Exp Rheumatol 2003;21:S154-7.

6. Bathon JM, Martin RW, Fleischmann RM, Tesser JR, Schiff MH, Keystone EC, et al. A comparison of etanercept and methotrexate in patients with early rheumatoid arthritis. N Engl J Med 2000;343:1586-93.

7. Breedveld FC, Weisman MH, Kavanaugh AF, Cohen SB, Pavelka K, van Vollenhoven $\mathrm{R}$, et al. The PREMIER study: a multicenter, randomized, double-blind clinical trial of combination therapy with adalimumab plus methotrexate versus methotrexate alone or adalimumab alone in patients with early, aggressive rheumatoid arthritis who had not had previous methotrexate treatment. Arthritis Rheum 2006:54:26-37.

8. St Clair EW, van der Heijde DM, Smolen JS, Maini RN, Bathon JM, Emery P, et al. Combination of infliximab and methotrexate therapy for early rheumatoid arthritis: a randomized, controlled trial. Arthritis Rheum 2004;50:3432-43.

9. Keystone EC, Kavanaugh AF, Sharp JT, Tannenbaum H, Hua Y, Teoh LS, et al. Radiographic, clinical, and functional outcomes of treatment with adalimumab (a human anti-tumor necrosis factor monoclonal antibody) in patients with active rheumatoid arthritis receiving concomitant methotrexate therapy: a randomized, placebo-controlled, 52-week trial. Arthritis Rheum 2004:50:1400-11.

10. Klareskog L, van der Heijde D, de Jager JP, Gough A, Kalden J, Malaise M, et al Therapeutic effect of the combination of etanercept and methotrexate compared with each treatment alone in patients with rheumatoid arthritis: double-blind randomised controlled trial. Lancet 2004;363:675-81.

11. Lipsky PE, van der Heijde DM, St Clair EW, Furst DE, Breedveld FC, Kalden JR, et al. Infliximab and methotrexate in the treatment of rheumatoid arthritis. Anti-Tumo Necrosis Factor Trial in Rheumatoid Arthritis with Concomitant Therapy Study Group. N Engl J Med 2000:343:1594-602

12. Bongartz T, Sutton AJ, Sweeting MJ, Buchan I, Matteson EL, Montori V. Anti-TNF antibody therapy in rheumatoid arthritis and the risk of serious infections and malignancies: systematic review and meta-analysis of rare harmful effects in randomized controlled trials. JAMA 2006;295:2275-85

13. Dixon WG, Watson K, Lunt M, Hyrich KL, Silman AJ, Symmons DP. Rates of serious infection, including site-specific and bacterial intracellular infection, in rheumatoid arthritis patients receiving anti-tumor necrosis factor therapy: results from the British Society for Rheumatology Biologics Register. Arthritis Rheum 2006:54:2368-76.

14. Wolfe F, Michaud K. Biologic treatment of rheumatoid arthritis and the risk of malignancy: analyses from a large US observational study. Arthritis Rheum 2007:56:2886-95.

15. van der Kooij SM, de Vries-Bouwstra JK, Goekoop-Ruiterman YP, van Zeben D, Kerstens PJ, Gerards AH, et al. Limited efficacy of conventional DMARDs after initial methotrexate failure in patients with recent onset rheumatoid arthritis treated according to the disease activity score. Ann Rheum Dis 2007;66:1356-62.

16. van Vollenhoven RF, Ernestam S, Cöster L, Dackhammar C, Forslind K, Geborek P, et al. Methotrexate monotherapy is clinically adequate in $29 \%$ of patients with early RA - initial open-label phase of the SWEFOT multicenter clinical trial. Ann Rheum Dis 2007:66(Suppl II)·P450.
17. Quinn MA, Conaghan PG, O'Connor PJ, Karim Z, Greenstein A, Brown A, et al. Very early treatment with infliximab in addition to methotrexate in early, poor-prognosis rheumatoid arthritis reduces magnetic resonance imaging evidence of synovitis and damage, with sustained benefit after infliximab withdrawal: results from a twelvemonth randomized, double-blind, placebo-controlled trial. Arthritis Rheum 2005; 52:27-35

18. van der Bijl AE, Goekoop-Ruiterman YP, de Vries-Bouwstra JK, Ten Wolde S, Han $\mathrm{KH}$, van Krugten MV, et al. Infliximab and methotrexate as induction therapy in patients with early rheumatoid arthritis. Arthritis Rheum 2007;56:2129-34.

19. Baumgartner SW, Fleischmann RM, Moreland LW, Schiff MH, Markenson J, Whitmore JB. Etanercept (Enbrel) in patients with rheumatoid arthritis with recent onset versus established disease: improvement in disability. J Rheumatol 2004;31:1532-7.

20. Taylor PC, Steuer A, Gruber J, McClinton C, Cosgrove DO, Blomley MJ, et al. Ultrasonographic and radiographic results from a two-year controlled trial of immediate or one-year-delayed addition of infliximab to ongoing methotrexate therapy in patients with erosive early rheumatoid arthritis. Arthritis Rheum 2006:54:47-53.

21. Goekoop-Ruiterman YP, de Vries-Bouwstra JK, Allaart CF, van Zeben D, Kerstens PJ, Hazes JM, et al. Clinical and radiographic outcomes of four different treatment strategies in patients with early rheumatoid arthritis (the BeSt study): a randomized, controlled trial. Arthritis Rheum 2005;52:3381-90.

22. Goekoop-Ruiterman YP, de Vries-Bouwstra JK, Allaart CF, van Zeben D, Kerstens PJ, Hazes JM, et al. Comparison of treatment strategies in early rheumatoid arthritis: a randomized trial. Ann Intern Med 2007;146:406-15

23. D'Agostino RB Jr. Propensity score methods for bias reduction in the comparison of a treatment to a non-randomized control group. Stat Med 1998;17:2265-81.

24. Wiles NJ, Lunt M, Barrett EM, Bukhari M, Silman AJ, Symmons DP, et al. Reduced disability at five years with early treatment of inflammatory polyarthritis: results from a large observational cohort, using propensity models to adjust for disease severity. Arthritis Rheum 2001;44:1033-42.

25. van der Heijde DM, van 't Hof M, van Riel PL, van de Putte LB. Development of disease activity score based on judgment in clinical practice by rheumatologists. J Rheumatol 1993:20:579-81.

26. Siegert CE, Vleming LJ, Vandenbroucke JP, Cats A. Measurement of disability in Dutch rheumatoid arthritis patients. Clin Rheumatol 1984;3:305-9.

27. van der Heijde D. How to read radiographs according to the Sharp/van der Heijde method. J Rheumatol 2000;27:261-3.

28. Bruynesteyn K, Boers M, Kostense P, van der Linden S, van der Heijde D. Deciding on progression of joint damage in paired films of individual patients: smallest detectable difference or change. Ann Rheum Dis 2005;64:179-82.

29. Kosinski M, Zhao SZ, Dedhiya S, Osterhaus JT, Ware JE Jr. Determining minimally important changes in generic and disease-specific health-related quality of life questionnaires in clinical trials of rheumatoid arthritis. Arthritis Rheum 2000;43:1478-87.

30. van der Klooster JM, Bosman RJ, Oudemans-van Straaten HM, van der Spoel J Wester JP, Zandstra DF. Disseminated tuberculosis, pulmonary aspergillosis and cutaneous herpes simplex infection in a patient with infliximab and methotrexate. Intensive Care Med 2003;29:2327-9.

31. Drossaers-Bakker KW, de Buck M, van Zeben D, Zwinderman AH, Breedveld FC Hazes JM. Long-term course and outcome of functional capacity in rheumatoid arthritis: the effect of disease activity and radiologic damage over time. Arthritis Rheum 1999:42:1854-60.

32. Scott DL, Pugner K, Kaarela K, Doyle DV, Woolf A, Holmes J, et al. The links between joint damage and disability in rheumatoid arthritis. Rheumatology (Oxford) 2000:39:122-32

33. Buch MH, Marzo-Ortega H, Bingham SJ, Emery P. Long-term treatment of rheumatoid arthritis with tumour necrosis factor alpha blockade: outcome of ceasing and restarting biologicals. Rheumatology (Oxford) 2004;43:243-4.

34. Rahman MU, Strusberg I, Geusens P, Berman A, Yocum D, Baker D, et al. Doubleblinded infliximab dose escalation in patients with rheumatoid arthritis. Ann Rheum Dis 2007;66:1233-8.

35. St Clair EW, Wagner CL, Fasanmade AA, Wang B, Schaible T, Kavanaugh A, et al. The relationship of serum infliximab concentrations to clinical improvement in rheumatoid arthritis: results from ATTRACT, a multicenter, randomized, double-blind, placebo-controlled trial. Arthritis Rheum 2002;46:1451-9. 